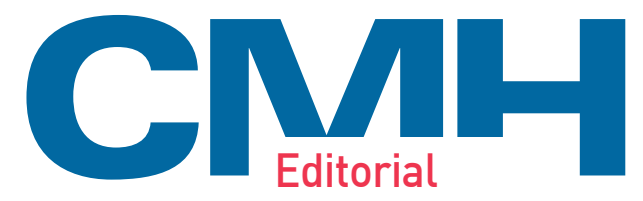

http://dx.doi.org/10.3350/cmh.2012.18.4.357

Clinical and Molecular Hepatology 2012;18:357-359

\title{
Elevated serum bilirubin levels are inversely associated with nonalcoholic fatty liver disease
}

\author{
Byoung Kuk Jang \\ Department of Internal Medicine, Keimyung University School of Medicine, Daegu, Korea
}

Keywords: Bilirubin; Nonalcoholic fatty liver disease

\section{See Article on Page 383}

Nonalcoholic fatty liver disease (NAFLD) has similar pathologic findings of alcoholic fatty liver but occurs in patients who drink little or no alcohol. ${ }^{1}$ Accumulation of excess fat in the liver is regarded as a clinical feature of insulin resistance and is known to be associated with metabolic syndrome components such as abdominal obesity, hypertension, type 2 diabetes and dyslipidemia. ${ }^{2,3}$ For this reason, NAFLD is currently considered as a form of metabolic syndrome occurring in the liver. ${ }^{4}$ NAFLD can progress from simple steatosis to nonalcoholic steatohepatitis (NASH) and cirrhosis which are accompanied with hepatic cellular destruction. ${ }^{5}$ It can even develop to hepatocellular carcinoma. ${ }^{6}$ As a result, patients with liver cirrhosis often have concomitant metabolic diseases such as diabetes and coronary heart disease and the major causes of their mortality are reported to be coronary vascular disease (CVD), extrahepatic malignancy and cirrhosis related events. ${ }^{7}$

Bilirubin is the end product of heme catabolism. Heme is degraded to biliverdin, cabon monoxide and ferrous iron by heme oxygenase (HMOX) and biliverdin is reduced to bilirubin by biliverdin reductase. Bilirubin is bound to albumin in the plasma and is delivered to the liver in the form of albumin-bound bilirubin. Albumin-bound bilirubin is conjugated with glucuronic acid by UDP-glucuronosyltransferase (UGT1A1) and is excreted to biliary duct in the form of bisglucuronosyl bilirubin. ${ }^{8}$ Bilirubin used to be regarded as a toxic metabolite in the central nerve system. ${ }^{9}$ However, in recent years, cytoprotective effects of bilirubin have been reported in a few studies. ${ }^{10-12}$ Frei et al reported that serum bilirubin significantly contributes to total antioxidant capacity. ${ }^{11}$ It was discovered that bilirubin had anti-inflammatory effects as well as acts as scavengers of reactive oxygen species, as it was mentioned above. ${ }^{13}$ In addition to bilirubin, experimental studies have found that enzymes involved in bilirubin metabolism also have several effects. In an experiment conducted with an animal model, it was shown that HMOX1 stimulated insulin products and reduced insulin resistance. ${ }^{14}$ It was also reported that biliverdin reductase has multiple functions affecting cell signaling and modulating immune system response $e^{15,16}$

In clinical practice, it has been reported that the level of serum bilirubin is related to several diseases. There have been a number of studies reporting a negative relation between serum bilirubin and CVD since Schwertner et al reported a negative relationship

\footnotetext{
Abbreviations:

CVD, coronary vascular disease; HMOX, heme oxygenase; NAFLD, non-alcoholic fatty liver disease; NASH, non-alcoholic steatohepatitis; UGT1A1, UDP-glucuronosyltransferase
}

\author{
Corresponding author : Byoung Kuk Jang \\ Department of Internal Medicine, Keimyung University School of \\ Medicine, 56 Dalseong-ro, Jung-gu, Daegu 700-712, Korea \\ Tel. +82-53-250-7088, Fax. +82-53-250-7088 \\ E-mail; jangha106@dsmc.or.kr
}


between serum bilirubin level and coronary artery disease. ${ }^{17,18}$ In addition, it was also reported that a high level of serum bilirubin reduced the risk of diabetes mellitus and diabetic nephropathy. ${ }^{19}$ Cheriyath et al reported that increased total bilirubin $(\geq 10$ $\mu \mathrm{mol} / \mathrm{L}$ ) was associated with $26 \%$ reduction in diabetes risk. ${ }^{20}$ In recent years, it was reported that serum bilirubin had a negative relation with metabolic syndrome, abdominal obesity and NAFLD. ${ }^{21,22}$ A study conducted with Taiwanese children showed that UGT1A1 promoter variants related to Gilbert syndrome was associated with the low risk of NAFLD and the levels of serum bilirubin were low in the patients with NAFLD. ${ }^{23}$

In this study by Kwak et al, they conducted a retrospective study with 17,348 people undergoing health checkups to examine the relationship between serum bilirubin levels and NAFLD. The prevalence of NAFLD decreased as a serum bilirubin level increased and a multivariate analysis confirmed a negative relation between serum bilirubin levels and the prevalence of NAFLD (odds ratio [OR] 0.88, 95\% confidence interval [CI], 0.80-0.97). This study was conducted with a large number of people undergoing health checkups and included both men and women and it reconfirmed the result of previous studies. However, there were a few limitations that needed to be addressed in this study. The first limitation was that alcohol consumption might not be accurately assessed since this study was conducted as a retrospective study with people undergoing health checkups. It is generally known that people tend to underestimate their alcohol consumption when answering a survey. ${ }^{24}$ Therefore, it was possible that a large proportion of alcoholic fatty liver patients might have included in this study.

The second limitation was that the level of total bilirubin was only measured and analyzed instead of measuring unconjugated bilirubin and conjugated bilirubin separately. Chang et al reported that the level of serum conjugated bilirubin was related to the occurrence of NAFLD and Kumar et al and Hjelkrem et al reported that the level of serum unconjugated bilirubin was related to the severity of NAFLD. ${ }^{25-27}$ In other words, currently, it is not clear that what type of bilirubin is associated with NAFLD. Therefore, further researches to identify this matter will be required in the future.

Summarizing several research results reported to date, serum bilirubin has protective effects on various diseases. Accordingly, studies have been conducted to find methods to artificially increase serum bilirubin. In some studies, UGT1A1 activity was partially inhibited by probenecid and atazanavir to induce iatrogenic Gilbert syndrome. ${ }^{28,29}$ In some other studies, it was reported that curcumin and sylimarin induced HMOX induction and subsequently increased insulin secretion in diabetes animal models resulting in the improvement of laboratory markers. ${ }^{30}$

In conclusion, this study, conducted with a large number of healthy populations, confirmed the inverse relationship between serum bilirubin level and the occurrence of NAFLD. Based on this result, further clinical studies on the disease prevention and treatment by controlling serum bilirubin level will be required in the future.

\section{Conflicts of Interest}

The author has no conflicts to disclose.

\section{REFERENCES}

1. Ludwig J, Viggiano TR, McGill DB, Oh BJ. Nonalcoholic steatohepatitis: Mayo Clinic experiences with a hitherto unnamed disease. Mayo Clin Proc 1980;55:434-438.

2. Speliotes EK, Massaro JM, Hoffmann U, Vasan RS, Meigs JB, Sahani DV, et al. Fatty liver is associated with dyslipidemia and dysglycemia independent of visceral fat: the Framingham Heart Study. Hepatology 2010;51:1979-1987.

3. Chen SH, He F, Zhou HL, Wu HR, Xia C, Li YM. Relationship between nonalcoholic fatty liver disease and metabolic syndrome. Dig Dis 2011;12:125-130.

4. Marchesini G, Brizi M, Bianchi G, Tomassetti S, Bugianesi E, Lenzi $\mathrm{M}$, et al. Nonalcoholic fatty liver disease: a feature of the metabolic syndrome. Diabetes 2001;50:1844-1850.

5. Adams LA, Lymp JF, St Sauver J, Sanderson SO, Lindor KD, Feldstein $A$, et al. The natural history of nonalcoholic fatty liver disease: a population-based cohort study. Gastroenterology 2005;129:113 121.

6. Bugianesi E, Leone N, Vanni E, Marchesini G, Brunello F, Carucci P, et al. Expanding the natural history of nonalcoholic steatohepatitis: from cryptogenic cirrhosis to hepatocellular carcinoma. Gastroenterology 2002;123:134-140.

7. Caldwell $S, \operatorname{Argo} C$. The natural history of non-alcoholic fatty liver disease. Dig Dis 2010;28:162-168.

8. Fabris L, Cadamuro M, Okolicsanyi L. The patient presenting with isolated hyperbilirubinemia. Dig Liver Dis 2009;41:375-381.

9. Hansen TW. Mechanisms of bilirubin toxicity: clinical implications. Clin Perinatol 2002;29:765-778, viii.

10. Stocker R, Yamamoto Y, McDonagh AF, Glazer AN, Ames BN. Bilirubin is an antioxidant of possible physiological importance. Science 1987;235:1043-1046.

11. Frei B, Stocker R, Ames BN. Antioxidant defenses and lipid peroxidation in human blood plasma. Proc Natl Acad Sci U S A 1988;85:9748-9752. 
12. Sedlak TW, Saleh M, Higginson DS, Paul BD, Juluri KR, Snyder SH. Bilirubin and glutathione have complementary antioxidant and cytoprotective roles. Proc Natl Acad Sci U S A 2009;106:5171-5176.

13. Vítek $L$, Schwertner HA. The heme catabolic pathway and its protective effects on oxidative stress-mediated diseases. Adv Clin Chem 214.

14. Ndisang JF, Jadhav A. Up-regulating the hemeoxygenase system enhances insulin sensitivity and improves glucose metabolism in insulin-resistant diabetes in Goto-Kakizaki rats. Endocrinology 2009;150:2627-2636.

15. Kapitulnik J, Maines MD. Pleiotropic functions of biliverdin reductase: cellular signaling and generation of cytoprotective and cytotoxic bilirubin. Trends Pharmacol Sci 2009;30:129-137.

16. Maines MD. New insights into biliverdin reductase functions: linking heme metabolism to cell signaling. Physiology (Bethesda) 2005;20:382-389.

17. Schwertner HA, Jackson WG, Tolan G. Association of low serum concentration of bilirubin with increased risk of coronary artery disease. Clin Chem 1994;40:18-23.

18. Djousse L, Levy D, Cupples LA, Evans JC, D'Agostino RB, Ellison RC. Total serum bilirubin and risk of cardiovascular disease in the Framingham offspring study. Am J Cardiol 2001;87:1196-1200; A4, A7.

19. Han SS, Na KY, Chae DW, Kim YS, Kim S, Chin HJ. High serum bilirubin is associated with the reduced risk of diabetes mellitus and diabetic nephropathy. Tohoku J Exp Med 2010;221:133-140.

20. Cheriyath P, Gorrepati VS, Peters I, Nookala V, Murphy ME, Srouji $\mathrm{N}$, et al. High Total Bilirubin as a Protective Factor for Diabetes Mellitus: An Analysis of NHANES Data From 1999 - 2006. J Clin Med Res 2010;2:201-206.

21. Lin LY, Kuo HK, Hwang JJ, Lai LP, Chiang FT, Tseng CD, et al. Serum bilirubin is inversely associated with insulin resistance and metabolic syndrome among children and adolescents. Atherosclerosis
2009;203:563-568.

22. Choi SH, Yun KE, Choi HJ. Relationships between serum total bilirubin levels and metabolic syndrome in Korean adults. Nutr Metab Cardiovasc Dis 2011 Jun 22. [Epub ahead of print]

23. Lin YC, Chang PF, Hu FC, Chang MH, Ni YH. Variants in the UGT1A1 gene and the risk of pediatric nonalcoholic fatty liver disease. Pediatrics 2009;124:e1221- e1227.

24. Hayashi PH, Harrison SA, Torgerson S, Perez TA, Nochajski T, Russell $M$. Cognitive lifetime drinking history in nonalcoholic fatty liver disease: some cases may be alcohol related. Am J Gastroenterol 2004;99:76-81.

25. Chang Y, Ryu S, Zhang Y, Son HJ, Kim JY, Cho J, et al. A cohort study of serum bilirubin levels and incident non-alcoholic fatty liver disease in middle aged Korean workers. PLoS One 2012;7:e37241.

26. Kumar R, Rastogi A, Maras JS, Sarin SK. Unconjugated hyperbilirubinemia in patients with non-alcoholic fatty liver disease: a favorable endogenous response. Clin Biochem 2012;45:272-274.

27. Hjelkrem M, Morales A, Williams CD, Harrison SA. Unconjugated hyperbilirubinemia is inversely associated with non-alcoholic steatohepatitis (NASH). Aliment Pharmacol Ther 2012;35:1416-1423.

28. McCarty MF. "latrogenic Gilbert syndrome"--a strategy for reducing vascular and cancer risk by increasing plasma unconjugated bilirubin. Med Hypotheses 2007;69:974-994.

29. Dekker D, Dorresteijn MJ, Pijnenburg M, Heemskerk S, RasingHoogveld A, Burger DM, et al. The bilirubin-increasing drug atazanavir improves endothelial function in patients with type 2 diabetes mellitus. Arterioscler Thromb Vasc Biol 2011;31:458-463.

30. Bonifaz V, Shan Y, Lambrecht RW, Donohue SE, Moschenross D, Bonkovsky HL. Effects of silymarin on hepatitis $C$ virus and haem oxygenase-1 gene expression in human hepatoma cells. Liver Int 2009;29:366-373. 